\title{
67
}

\section{Bytes for Belfast: personal development for young people in disadvantaged areas through information technology}

\author{
John Anderson \\ Joe Reynolds \\ Department of Education for Northern Ireland \\ County Down \\ Northern Ireland
}

\begin{abstract}
Bytes for Belfast is an experimental pilot programme designed to attract unemployed and demotivated young people who have few, if any, academic qualifications into an environment of information technology (IT). This environment is meant to accelerate their own personal development by using the technology in a creative, productive and enjoyable way. The paper explains the rationale for Bytes for Belfast and how it works, touches on the issues arising and, illustrated by examples of its success. It also asks how the lessons of Bytes can reshape the way educators think about technology and its usefulness for young people who have not responded to traditional teaching methods. Bytes for Belfast stresses the importance to the individual of the use of technology to create different social and educational outcomes rather than simply facilitating or accelerating the traditional successes of the educational system.
\end{abstract}

Main conference themes: learner centred learning, social issues

Educational areas: vocational education

Study topics:

Secondary keywords: culture, motivation, pedagogy, policy 


\section{INTRODUCTION}

Belfast needs no introduction. 25 years of terrorism have compounded the social and economic problems of deprivation and unemployment typical of many inner cities. Only the acuteness of the problem varies: in some areas in west and north Belfast, unemployment stands at $80 \%$ and has done so for 3 generations. Northern Ireland schoolleavers achieve the highest standards in the United Kingdom in public examinations, but this achievement is matched by a proportion of pupils leaving school with no qualifications which proportion has until recently been the highest in the UK. Government finances an extensive network of organizations and agencies which provides training for all unemployed school leavers. Yet some are not motivated and reject even this life-line.

A preliminary investigation was funded by the Department of Education for Northern Ireland (DENI) into the feasibility of implementing a project which would aim to use IT as a means of rehabilitating low-attaining, socially disaffected, young people. The report concluded that there are few suitable activities for the 'unattached' youth; youth clubs have not adapted to meet the changing needs of these young people (or have barred them from entry); the target group is deeply sceptical of any 'initiative' where they know employment cannot be guaranteed at the end and they do not see potential skills in using computers as a resource on which to build.

The investigator described such young people as being at risk from the diversions of alcohol and drug abuse, car theft and petty crime; to which were added the very real dangers of paramilitary involvement. Their abuse of substances, 'down on the riverbank' has alienated them, causing tensions which drive away even those in their own community who might consider their needs. Such are the threats facing the young people between ages 16 and 25 in the target group for Bytes for Belfast, the eldest of which have grown up knowing nothing but violence since the rioting began in Belfast in 1969.

\section{How the project came about}

There has been much rhetoric accompanying the IT revolution about the 'personal empowerment' of microcomputers. Where is this true? And, if it is true, can it be tested in the most adverse of circumstances where people are most disempowered by their poor literacy, numeracy and lack of self-esteem? Bytes was to become a high risk venture aimed at a target group of whom it is often asked: did they fail school, or did school fail them? And if school failed them, can IT save them?

The rationale for Bytes for Belfast is unique: it represents a vision about the personal empowerment of IT. However, it also owes much to a variety of 
community education projects, many in the USA [1]. Prime amongst these is the 'Bullets to Bytes' project, an innercity concept initiated by Dr. Oscar Arias, former president of Costa Rica, and by the former mayor of San Jose in California, Tom McEnery, who subsequently played an influential role in the development of the Belfast project and in establishing links with the Apple Corporation who donated $\$ 250,000$ of equipment, the first such donation made outside the USA.

Also very significant were numerous other projects, such as that run by Alan Shaw from the Media Lab, Massachusetts Institute of Technology, who works with black street gangs developing their electronics and programming skills using Apple computers and Lego Technic kit, including sensors and devices prototyped in the Media Lab. The young people sell their technology skills back to their neighbourhood, by fixing domestic electronic appliances. As Alan Shaw says; "They are not just fixing appliances, they are fixing relationships".

Bytes for Belfast has also become an international affiliate of the 'Playing to Win' (PTW) network of USA community computer centres. The inspiration of network president Antonia Stone, a former New York high school teacher, made the network grow, in the heat of 1978 Harlem, out of the local community computer centre to now embrace centres in Boston, New York and Washington. The mission of PTW is "to confront the prospect that in an increasingly technological society people who are socially and economically disadvantaged will become further disadvantaged if they lack access to technology or to assistance to learning to use these technologies effectively". PTW staff refuse to believe that literacy is a prerequisite for using computers productively; they also find that computers provide a medium of expression for the alienated and angry. As Toni Stone says; "Computers give the individual power and control in return for involvement".

A major issue for the founders of Bytes for Belfast is whether you can recreate these personal visions by setting up a project in a somewhat bureaucratic fashion. An evaluation carried out by an international team concluded that the project:

... has demonstrated successfully that information technology (IT) can be used as a mediating tool to foster rapid personal and social development in young people 'at risk' to themselves and their communities [2].

The statement of mission adopted by the staff states that Bytes will:

provide opportunities in an informal setting for young people to accelerate their own personal development through the creative and enjoyable use of technology; 
actively seek out those who because of their social environment or personal experience face obstacles to personal advancement;

assist young people to achieve their full potential through progression to further education, purposeful training or the world of work.

Bytes aims to enable members of the target group to work creatively, to engage in problem solving, to work collaboratively with each other, the local community and more widely and to be productive and ultimately to be selfreliant.

In short, the aims of the project are to harness the creative potential of IT in ways which will initially engage the interest of the target group and will overcome their reluctance to expose themselves to new experiences where there is a risk of failure. And subsequently lead them on to experience success which will build their selfconfidence and replace the arrogant and aggressive posturing which conceals real insecurity, with genuine self-esteem.

\section{How Bytes works successfully}

Four Bytes for Belfast centres opened between June and August 1993 and have been integrated into existing youth and community facilities located in areas of north and west Belfast which suffer most from economic and social problems and in which the threat to young people of paramilitary involvement was greatest. Operating costs are funded by the Department of Education from the resources of 'Making Belfast Work', an innercity regeneration initiative. Two full-time staff are employed in each centre, with a balance of experience in IT and in social work/personal development.

Each centre is equipped with a basic network of 8 Apple computers and a variety of productivity tools, simulation packages, Lego Technic kit, electronic mail and peripherals such as scanners and CD ROM drives. More recently video cameras and specialist digital video editing computers and software have been purchased. Different interests have emerged in individual centres. A local musician brings his computer driven electronic music equipment to one centre and some users have produced music good enough for public performance. Another centre has been loaned a specialist cutting lathe for producing plastic computer designed signs and symbols for rally cars. Bytes aims for a 'product every time' to give tangible reality to productive achievement. The projects in which young people engage can be very wide ranging, from the production of simple computer art (sometimes posters, sometimes made into fridge magnets and badges), to desk-top published local newspapers, poetry (and in one case an autobiographical novel) and 'Quick-Time' computer movies. 
The evaluators have pointed out that "the volume of traffic through the Centre is broadly satisfactory". Interestingly, both evaluators and government funders agree that success is best measured in qualitative terms. The most powerful evidence of progression comes in the form of anecdotes arising from the day to day challenge for Bytes staff which is to creatively inspire users, to set fire to their imagination so that they engage productively and successfully with 'difficult' IT tasks, no matter how simple or sophisticated the IT resource used. The evaluators said:

The clients, the young people who come in and out of the Bytes Centres, are the heart and soul of the Bytes for Belfast project. They bring it to life and keep it alive and they are the reason for living.

For example, one boy, expelled from his school, began to attend Bytes and, having produced and carefully compiled a portfolio of his IT work, wrote to his headteacher, sent the portfolio and asked to be taken back to school, where he has attended successfully since. Another, on probation and referred by a social worker who had given up in despair, refused to speak a word to Bytes staff or touch a keyboard for the first week. In time he became so enamoured of computers that he decorated the centre with his computer art, graduated to regular domestic duties in the centre and, one day when staff left for an hour and jokingly said 'the windows are a 'bit dirty', were amazed to find the large shop-front windows sparkling clean on their return.

Some users have produced computer work to high standards, sometimes prize-winning. A group of car thieves from one centre finished second in a European competition of the 'Young Enterprise' network; a considerable achievement especially as their competitors were generally older, better academically qualified and were following pre-university business courses. Sometimes the possession of IT skills can overcome other barriers as one skilful Bytes member discovered when a neighbouring youth club (from the other religious community) paid him to set up their new computer and to visit their centre regularly to provide training.

Others have made substantial progress in personal terms. The production of a local news sheet led to a visit to a local daily newspaper which in turn prompted one young man to apply successfully for a van driver's post with the company. Not at all technological, but in an environment of ubiquitous unemployment, a considerable achievement. Another young man spend his first afternoon at Bytes designing a Valentine card, complete with mandatory emotional greeting. However, in a social environment where young men can be emotionally desensitized far beyond normal teenage reticence, this was (according to his astonished probation officer) a truly remarkable event. Such 
successes are not readily quantifiable. The case studies illustrate genuine progress with a target group for whom all other lawful forms of diversion and education have failed. Only when young people leave Bytes to take formal training, to gain work or to concentrate their time actively seeking work, can Bytes claim another success.

For many it is the development of self-esteem and personal motivation which Bytes offers that is far more important than any of the technological applications which they may learn. One USA visitor, accustomed to the intensity of discussion and action on local political, social and environmental issues amongst Harlem teenagers, asked if the same happened in Bytes: no, was the reply, we get enough of that outside, Bytes is our 'refuge from politics'. However, working in Bytes has attendant dangers; some of the centres are in street-front locations and all are in areas where terrorist attacks and shootings have happened on the doorstep with frequency. Staff and their property have been threatened for no apparent reason. They remain sanguine, surprising even themselves. They realize that, in the sense that Bytes centres are a sanctuary from violence, they are also a place where users feel able to blow off steam in the only way they know. They provide a 'home' environment, missing from the lives of many of the young people, and a place which provides focus, purposeful activity and possible achievement.

\section{And for the future?}

An evaluation of Bytes was carried out in the autumn of 1994 [2] to provide evidence and guidance on a number of issues:

\section{To make recommendations on the future of the project and what changes, if any, are needed.}

How can Bytes centres offer progress in learning through and about the technology? The evaluators commented that for many clients IT is likely to become a central concern because IT skills are marketable. They recommended that the development of personal portfolios of work and simple profiles (of IT progress and of personal and social development) are equally important pieces of evidence which would promote the progress of young people and their successful 'exit' to training or employment. The evaluators also commended the importance of building 'exit bridges' to help young people move on, to ensure that Bytes does not start to replicate counselling and training services already available elsewhere or, worse still, become an alternative form of dependency.

How does Bytes deal with young people outside the target group? Bytes is a remedial programme. Whilst it is attractive to work with young people who have at least some motivation rather than seeking out the deeply unwilling, the 
project's purpose is to redirect young people who have not found success through established systems. Should Bytes attempt to address those who are under 16, who have been excluded from school and would otherwise be roaming the streets? Some USA projects take the view that catching disinterest at a younger age has a preventive aspect, reducing the potential for 'school failure' at a later date. Bytes does not aim to provide preventive action, the responsibility for this remains with the schools.

The imbalance of male and female users is a problem. Young men, predominantly, are attracted both to violence and to technology. Against this backdrop, maintaining gender balance has proved difficult, especially for those centres with shop-window fronts which appear to be 'techy, male environments' to those outside. One Bytes centre established a gender balance amongst its users by attracting young women in groups (such as single mother clubs) some of whom become sustained users on an individual basis; another employs female youth workers to undertake outreach work.

\section{To consider the balance, in future funding, between government funding and sponsorship from business and industry.}

No USA project of this kind is, to our knowledge, a self-financing venture- not even when they set out to cover incidental costs from a small membership subscription. All depend on government or other forms of sponsorship. The trustees of Bytes of Belfast have therefore two questions to address: what counts as acceptable evidence that money spent on Bytes is a good investment of public funds and how can business and industry be persuaded to make a contribution which provides a measurable return of private sector investment. Bytes is, in essence, a programme aimed at 'social inclusion' making effective outreach to the socially excluded; as such, it makes a legitimate call on public funds. On the other hand, solid evidence of the 'throughput' to the world of training and employment derived from the portfolios and profiles of progress is the key to attracting a balance of private sector sponsorship. For example, the requirements of Northern Ireland's fair employment legislation mean that employers must invite applications from both communities; not always easy given the degree of physical division in some areas. Bytes can offer direct access to considerable numbers of these young people who, for historical reasons, would not ordinarily be part of the normal round of job and training applications which marks the progression of young people from school to working life. Bytes aims to instil motivation and a sense of independence which will prompt participants to apply for work and contributes to making them attractive prospects for employers. In the absence of Bytes many young people are condemned to the condition of unemployment because it has become the normal expectation for adults, especially men, in their locality. 


\section{To draw up guidelines for the effective establishment of new Bytes centres}

The evaluators took the view that the key characteristics and basic framework for Bytes Centres have worked and should not be substantially altered. They advise that the 'Bytes for Belfast philosophy' needs to be protected in any expansion by requiring an affirmative commitment to it, to networking and to cross-community collaboration (especially important in Northern Ireland society). They explore a number of possible models including the 'franchising' of the philosophy and pedagogy to communities wishing to set up a new centre and recommend consideration of a 'Bytes for All' initiative for the province as a whole.

\section{To clarify policy and practice lessons for schools and other providers of training for the target group.}

The evaluators concluded that the lessons from Bytes are relevant to schools, trainers and others who may already be well equipped with computers for the use of young people in the target group. They comment that the process of transforming young lives in contexts enriched by IT, while proven, is a complex one which "cannot be left to occur, as if by magic, when young people deemed to be 'at risk' are let loose on computers." It requires trained professionals who know how to use the computer as a mediating tool to bring about changes in self perception and self worth. This process involves taking risks within 'a well ordered pedagogy' with those who are 'anxious to wield power but inexperienced in self control'. While the lessons can be transferred to schools and youth clubs-and they recommend that Bytes enters into partnership with education providers- this needs to be done with great care and may have to be seen as a long-term exercise. It will require a commitment to the view that IT can be used for successful, productive and creative fun and fulfilment rather than simply for direct teaching in IT skills. Such an approach requires different 'frameworks for control' than those already established in schools and clubs.

\section{CONCLUSION}

One reason for the Department of Education for Northern Ireland to be involved in Bytes rests with its wider implications for the use of IT. Other reasons include the need to promote social inclusion, address marginalization of innercity youth, to develop links between communities, education and the young people for whom the project has been created. Specifically, there are lessons for all educators in the employment of technology for learning. There 
are lessons for technologists about the uses of technology by young people who do not conform to traditional methods of teaching. Bytes offers the prospect of showing developers how technology should be modified to meet the needs of individuals rather than allowing the technology to shape the activities of its users. This is the distinction between being part of the technology revolution rather than being subject to the revolution. The initial success of Bytes for Belfast suggests that the value of the technology lies not in its capacity to shape the lives of individuals but in its ability to be shaped, so as to increase the personal success and satisfaction of everyone, and especially the young, regardless of personal circumstance. This is the goal of educators and it is not new; but the capacity and availability of the technology to help achieve it are changing. The prospects for widening the success of education are enhanced, and we hope that Bytes for Belfast has made a contribution which will be emulated.

\section{REFERENCES}

1. Anderson, J. (1992) Note of visits to see community action work in Boston, New Haven, New York, Newark and Washington. (unpublished)

2. McMahon, H., Brown, J., Collins, J. and Stone, A. (1995) An Evaluation of the Bytes for Belfast Project. (unpublished) 